\title{
CONCERNS FOR EQUITY AND THE OPTIMAL CO-PAYMENTS FOR PUBLICLY PROVIDED HEALTH CARE
}

\author{
MiCHAEL HOEL
}

CESIFO WORKING PAPER NO. 1620

CATEgOry 1: Public FinANCE

DECEMBER 2005

An electronic version of the paper may be downloaded

- from the SSRN website:

www.SSRN.com

- from the CESifo website:

www.CESifo-group.de 


\title{
CONCERNS FOR EQUITY AND THE OPTIMAL CO-PAYMENTS FOR PUBLICLY PROVIDED HEALTH CARE
}

\begin{abstract}
In countries where health care is publicly provided and where equity considerations play an important role in policy decisions, it is often argued that an increase in co-payments is unacceptable as it will be particularly harmful to the less well-off in society. The present paper derives socially optimal co-payments in a simple model of health care where people differ in income and in severity of illness. The social optimum depends on the welfare weights given to persons with different levels of expected utility. Increased concern for equity may increase optimal co-payments for illnesses with homogeneous severity across the population. For illnesses where the severity varies strongly across the population, optimal copayments go down as a response to increased concern for equity, provided income differences in the society are sufficiently small.
\end{abstract}

JEL Code: D63, H42, H51, I18.

Keywords: public health, co-payments, equity concerns.

\author{
Michael Hoel \\ Department of Economics \\ University of Oslo \\ P.O. Box 1095 Blindern \\ 0317 Oslo \\ Norway \\ mihoel@econ.uio.no
}

November 14, 2005.

The paper was presented at the 4th Norwegian-German Seminar in Public Economics. Several participants at the conference, and in particular Silke Uebelmesser and Tomer Blumkin, gave useful comments and suggestions. Useful comments were also given by participants at a seminar at the Department of Economics, University of Oslo, in particular by Vidar Christiansen, and by Per-Olov Johansson and Albert Ma. I gratefully acknowledge financial support from the Research Council of Norway through HERO - Health Economic Research Programme at the University of Oslo. 


\section{Introduction}

From the insurance literature it is well known that positive co-payments have two effects ${ }^{1}$ : On the one hand they reduce social efficiency by reducing the risk sharing properties of insurance. On the other hand positive copayments increase social efficiency by reducing moral hazard. One important type of moral hazard for health care is that if the price the patient pays for some treatment is zero or low, the patient will purchase treatment even if the willingness to pay for the treatment is considerably lower than the cost of providing treatment. The optimal size of co-payments balances the two considerations above, see e.g. Zeckhauser (1970), Ma and Riordan (2002).

In countries where health care is publicly provided and where equity considerations play an important role in policy decisions, it is often argued that an increase in co-payments is unacceptable as it will be particularly harmful to the less well off in the society. The present paper gives a critical discussion of this issue. Within a simple model of health care where people differ in income and in severity of illness, it is shown in section 2 who gains and who loses from an increase in the co-payment for a particular treatment. The socially optimal co-payment is then derived by maximizing the sum of a concave transformation of expected utility for each person (section 3). The concave transformation reflects equity considerations, giving a person lower weight in the social welfare function the better off this person is in terms of expected utility. In section 4 it is shown how more concern for equity ("more concavity") affects the optimal co-payment. Section 5 concludes.

\section{Co-payment, taxation, and individual wel- fare}

The welfare of a person is given by $u(y-t)$ if healthy, where $t$ is a tax per person (same for everyone, see below) and $y$ is income net of any taxation other than $t$. The function $u$ is the same for everyone, while $y$ varies among

\footnotetext{
${ }^{1}$ See e.g. Arrow $(1963,1968)$, Pauly (1968), Shavell (1979).
} 
the population. For each person there is a probability $\pi$ (same for everyone) that the person becomes ill. In this case the welfare level of the person is $u(y-t)-\ell$ if untreated, where $\ell$ may vary among persons. The illness can be completely cured by a treatment that $\operatorname{costs} c$ (same for all treatments). ${ }^{2}$ The price that a patient must pay for this treatment is $p \in[0, c]$.

If a person becomes ill he or she will choose treatment if and only if

$$
u(y-t-p) \geq u(y-t)-\ell
$$

Obviously, a person with $\ell>0$ will choose to be treated if $p$ is zero or sufficiently close to zero, no matter how low $y$ is. For higher values of $p$, some or even all persons may choose not to be treated. A person is more likely to choose treatment the higher are $y$ and $\ell$ and the lower is $p$. It is useful to denote the set of people who choose treatment by $\Omega(p)$, i.e.

$$
\Omega(p)=\{y, \ell \mid u(y-t-p) \geq u(y-t)-\ell\}
$$

The set $\Omega(p)$ obviously depends on how $y$ and $\ell$ are distributed in the population. We assume that the joint distribution function is $F(y, \ell)$, and without loss of generality we assume that all values of $y$ and $\ell$ in the population are in the range $[0,1]^{3}$

Denoting the expected utility of a person by $v(y, \ell, p)$, we have

$$
v(y, \ell, p)=(1-\pi) u(y-t)+\pi \max [u(y-t)-\ell, u(y-t-p)]
$$

The size of the co-payment will affect the revenue requirement of the government. There are two reasons for this. First, the higher is the copayment, the lower is the cost paid by the government per treatment. Second, the higher is the co-payment, the fewer persons will choose to be treated. We shall assume that any change in the government's revenue requirement is met by a corresponding change in the tax rate $t$ that is the same for everyone. In

\footnotetext{
${ }^{2}$ The assumptions of a separable utility function and that the illness can be completely cured simplify the formal analysis, but are not essential for the main results.

${ }^{3}$ Formally, we assume $F(y, 0)=F(0, \ell)=0 \forall(y, \ell) \in[0,1]$ and $F(1,1)=1$.
} 
Section 5 we give a discussion of this assumption and of the consequences of relaxing it.

Denoting the share of the population that is treated by $\omega(p)$, the relationship between the size of the co-payment and the tax rate $t$ and is formally given by

$$
t(p)=\pi \cdot(c-p) \cdot \omega(p)
$$

It follows that

$$
t^{\prime}(p)=-\pi \omega(p)+\pi \cdot(c-p) \cdot \omega^{\prime}(p)
$$

which is negative since $\omega^{\prime}(p)$ is negative.

If $p$ is sufficiently small, everyone will choose treatment provided $\ell>0$ for everyone. In other words, $\omega(p)=1$ and $\omega^{\prime}(p)=0$ for sufficiently low values of $p$. For sufficiently high values of $p$, some people will choose not to be treated, i.e. $\omega(p)<1$. From (4) and (5) it therefore follows that

$$
\begin{aligned}
& -t^{\prime}(p)=\pi \text { for } p \text { so small that } \omega(p)=1 \\
& -t^{\prime}(p)<\pi \text { for } p \text { sufficiently close to } c
\end{aligned}
$$

For intermediate values of $p$, we may very well have $-t^{\prime}(p)>1$, since there is nothing that rules out "large" values of $-\omega$.

We are now ready to see how the expected utility $v(y, \ell, p)$ of a particular person depends on the size of the co-payment. To see this, we distinguish between those who choose treatment and those who don't: For those who choose not to be treated, it follows from (3) that

$$
\frac{\partial v(y, \ell, p)}{\partial p}=\left[-t^{\prime}(p)\right] u^{\prime}(y-t)>0
$$

For these persons (which include those with "low" income if $p$ initially is large enough), an increase in co-payments is thus unambiguously desirable. The interpretation is obvious: Since these persons in any case are choosing not to be treated, they are not directly affected by the increase in the co-payment. 
However, they gain from the tax reduction that is implied by the increase in the co-payment.

For those who choose to be treated, it follows from (3) that

$$
\frac{\partial v(y, \ell, p)}{\partial p}=(1-\pi)\left[-t^{\prime}(p)\right] u^{\prime}(y-t)+\pi\left[-t^{\prime}(p)-1\right] u^{\prime}(y-t-p)
$$

In this expression, the first term is positive. We cannot unambiguously sign the second term without knowing more about $t(p)$ than $t^{\prime}(p)<0$. However, the concavity of $u$ implies that $u^{\prime}(y-t)<u^{\prime}(y-t-p)$ when $p$ is positive. It therefore follows from (8) that

$$
\frac{\partial v(y, \ell, p)}{\partial p}<\left[-t^{\prime}(p)-\pi\right] u^{\prime}(y-t-p)
$$

From (6) it follows that the LHS of (9) is negative for $p$ sufficiently close to 0 , and for $p$ sufficiently close to $c$. From (7) and (9) we therefore have the following proposition:

Proposition 1 If the initial co-payment is sufficiently low, everyone chooses to be treated, and a small increase in the co-payment will make everyone worse off. If the initial co-payment is sufficiently close to the treatment cost and some people choose to be untreated at this co-payment, those who have chosen not to be treated gain from an increase in the co-payment, while those who have chosen to be treated lose from an increase in the co-payment.

Figure 1 illustrates how $v$ will depend on the size of the co-payment for a typical person. If $p$ is so low that everyone chooses treatment (below $p^{0}$ in Figure 1), it follows from (6) that (8) can be rewritten as

$$
\begin{gathered}
\frac{\partial v(y, \ell, p)}{\partial p}=(1-\pi) \pi\left[u^{\prime}(y-t)-u^{\prime}(y-t-p)\right]<0 \\
\text { if } \omega(p)=1
\end{gathered}
$$

where the inequality sign follows from the concavity of $u$. A positive copayment can thus only be optimal if it is set so high that it makes some persons choose not to be treated. 
Figure 1: Expected utility as a function of the size of the co-paymant

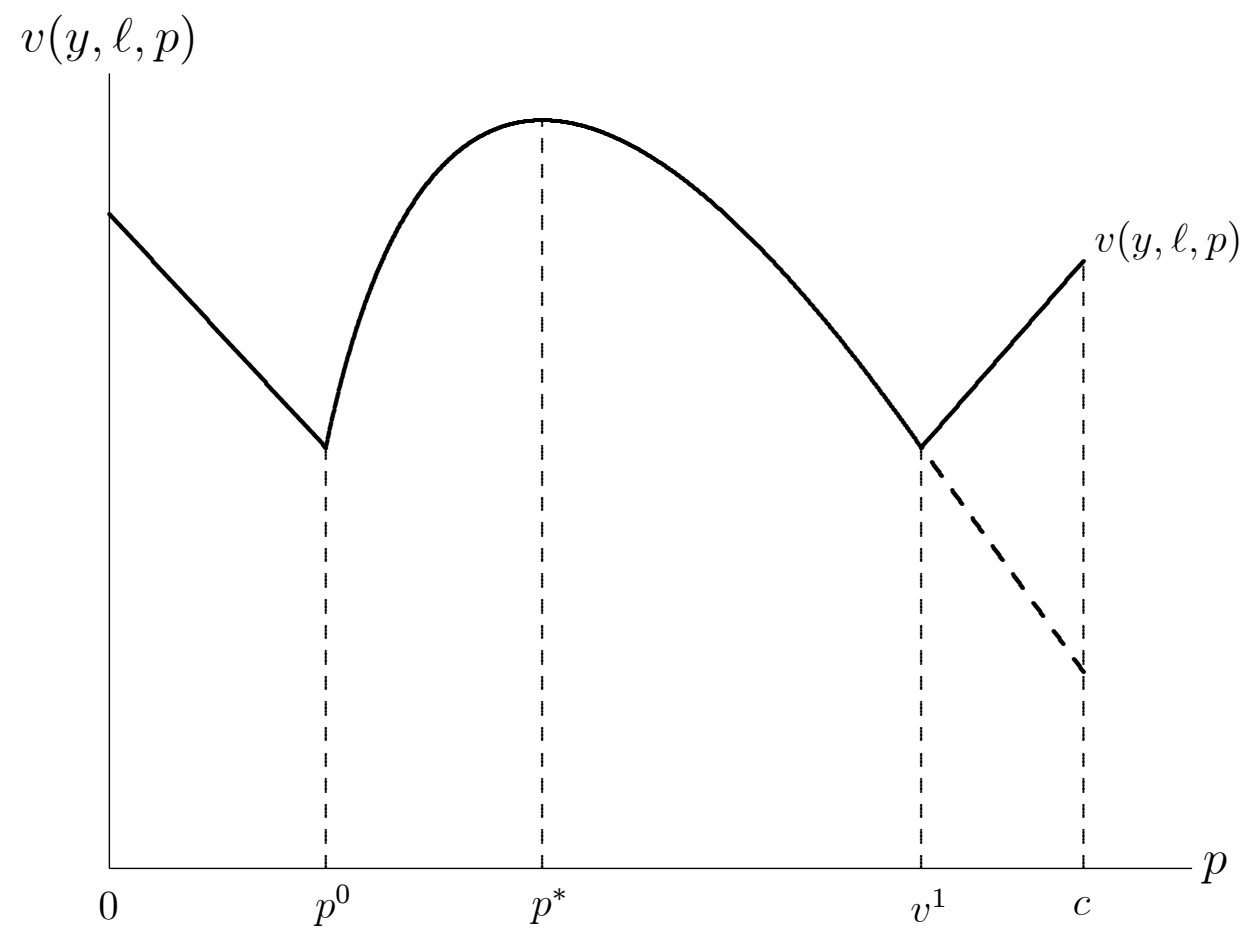

As $p$ increases beyond $p^{0}$, more and more persons choose not to be treated. The person illustrated by Figure 1 chooses treatment provided the co-payment does not exceed $p^{1}$. For $p>p^{1}$ expected utility is increasing in $p$, cf. (7). In Figure 1, $v$ is strictly concave for $p \in\left(p^{0}, p^{1}\right)$. Generally, this need not be the case. And even if $v$ is strictly concave for $p \in\left(p^{0}, p^{1}\right)$ with a local maximum at $p^{*}$, it is not obvious which of the three values $v(y, \ell, 0)$, $v\left(y, \ell, p^{*}\right)$ and $v(y, \ell, c)$ is highest.

\section{Co-payment and social welfare}

The objective of the government is to maximize the sum of welfare for all persons. However, for a government concerned about equity it is not reasonable to assume that this sum is unweighted. If the government cares about equity, it is reasonable to assume that persons with low expected utility have a higher weight in the sum of welfare than persons with high expected util- 
ity. In the hypothetical case of the government being perfectly informed about everyone's income earning abilities and health characteristics ( $\ell$ in the present analysis), lump-sum taxation could be used to obtain whatever distributional objectives the government had. In this case everyone would have the same welfare weight (on the margin) after the lump-sum taxation had been applied. In practice the government does not have perfect information about individuals' earning abilities and health characteristics. Distributional considerations must therefore be achieved through distortionary taxation. In this case it is not optimal to redistribute so much that marginal welfare weights are equalized across the population.

To capture distributional considerations, we assume that the government maximizes the sum over all persons of a concave transformation of expected utilities, i.e. over $\Phi(v(y, \ell, p))$ where is $\Phi$ is increasing and concave. The social objective function is thus given by

$$
W=\iint_{(y, \ell) \in[0,1]} \Phi(v(y, p, \ell)) d F(y, \ell)
$$

This expression can be illustrated by a Figure similar to Figure 1. In particular, since $p^{0}$ is the same for everyone, we typically get a local minimum at $p^{0}$ or somewhere to the right. The value $p^{1}$ varies among persons, so the aggregate curve will not have a kink at $p^{1}$ as in Figure 1. However, we may very well have at least one non-concave section of the curve for aggregate welfare in addition to the area near $p^{0}$. It is clear from Figure 1 that even if we find a local optimum with a positive co-payment, this optimum must be compared with the case of no co-payment and possibly also with other local optima with positive co-payments.

From now on we only consider the case of an interior optimum, i.e. the optimal $p$ is in the interval $(0, c)$. Differentiating (11) with respect to $p$ and using (7) and (8) gives the following first-order condition for the socially 
optimal co-payment, where we use the shorthand notation $v$ for $v(y, \ell, p)$ :

$$
\begin{aligned}
(1-\pi)\left[-t^{\prime}(p)\right] & \iint_{(y, \ell) \in[0,1]} \Phi^{\prime}(v) u^{\prime}(y-t) d F(y, \ell) \\
& +\pi\left[-t^{\prime}(p)\right] \iint_{(y, \ell) \notin \Omega(p)} \Phi^{\prime}(v) u^{\prime}(y-t) d F(y, \ell) \\
& -\pi\left[1+t^{\prime}(p)\right] \iint_{(y, \ell) \in \Omega(p)} \Phi^{\prime}(v) u^{\prime}(y-t-p) d F(y, \ell)=0
\end{aligned}
$$

The two first terms in this expression are are positive, implying that the last term is negative, i.e. we must have $1+t^{\prime}(p)>0$ at the optimal value of $p$. We shall use the expression above to answer the question what is the effect on the optimal co-payment of an increase in the concern for equity?

\section{Co-payments and equity concerns}

Consider a change in the function $\Phi(v)$ in the direction of stronger preferences for equity, i.e. a "more concave" function. More precisely, let $\Phi(v)$ be replaced by $\Phi^{*}(v) \equiv f(\Phi(v))$ where $f^{\prime}>0$ and $f^{\prime \prime}<0$. Calling $\Phi^{\prime}(v)$ and $\Phi^{* \prime}(v)$ the "marginal welfare weights" before and after the change, the change in marginal welfare weights is given by $\delta(v)=\Phi^{* \prime}(v)-\Phi^{\prime}(v)$. Since the level of the function $f^{\prime}$ is of no importance, it is convenient to chose this level so that

$$
\iint_{(y, \ell) \in[0,1]} \delta(v(y, \ell, p)) u^{\prime}(y-t) d F(y, \ell)=0
$$

It is easy to verify that the definition of the function $\delta(v)$ implies that $\delta^{\prime}(v)<0$ at the value of $v$ giving $\delta(v)=0$. Denoting this value of $v$ by $v^{*}$ it therefore follows from (13) that $\delta(v)>0$ for $v<v^{*}$ and $\delta(v)<0$ for $v>v^{*}$. In words, marginal welfare weights increase for persons with "low" expected utility $\left(v<v^{*}\right)$ and decline for persons with "high" expected utility $\left(v>v^{*}\right)$.

The normalization given by (13) implies that the first of the three terms in (12) does not change as the function $\Phi(v)$ changes. The total change in 
the LHS of (12) is given by (ignoring the term $\pi$ )

$$
\begin{aligned}
& \Delta=\left[-t^{\prime}(p)\right] \iint_{(y, \ell) \notin \Omega(p)} \delta(v) u^{\prime}(y-t) d F(y, \ell) \\
&-\left[1+t^{\prime}(p)\right] \iint_{(y, \ell) \in \Omega(p)} \delta(v) u^{\prime}(y-t-p) d F(y, \ell)
\end{aligned}
$$

If we can sign $\Delta$, we also know how the optimal co-payment $p$ changes as a response to the change in the function $\Phi(v)$ : If $\Delta$ is positive (negative) the LHS of (12) becomes positive (negative) when $\Phi(v)$ is replaced by $\Phi^{*}(v)$. To restore equality, it therefore follows from the second order condition that $p$ must increase (decline).

It is not possible to unambiguously sign $\Delta$ for the general case. It is therefore useful to consider the special cases in which the heterogeneity in the population is in either preferences or income, but not both.

\subsection{Heterogeneous preferences}

In this special case we assume that the income $y$ is the same for everyone, but that the values of $\ell$ varies in the population. Expected utility of a person therefore only depends on this person's value of $\ell$. A person with a value of $\ell$ above $u(y-t)-u(y-t-p)$, henceforth denoted $L$, will choose to be treated (cf. the discussion of equation (1) in Section 2), giving this person an expected utility equal to $(1-\pi) u(y-t)+\pi u(y-t-p)$. A person with a value of $\ell$ below $L$ will choose not to be treated, giving this person an expected utility equal to $(1-\pi) u(y-t)+\pi[u(y-t)-\ell]$, which is higher the lower is $\ell$. The relationship between $v$ and $\ell$ is illustrated in Figure 2 .

Restricting ourselves to the case where the function $\delta(v)$ is continuous, the critical value $\ell^{*}$ corresponding to $v^{*}$ must lie below $L$, i.e. all of the persons choosing to be treated and some of the persons choosing not to be treated must get a higher marginal welfare weight as a consequence of the increased concern for equity (see Figure 2). For this case we can rewrite (14) as 
Figure 2: Expected utility as a function of the severity of the illness

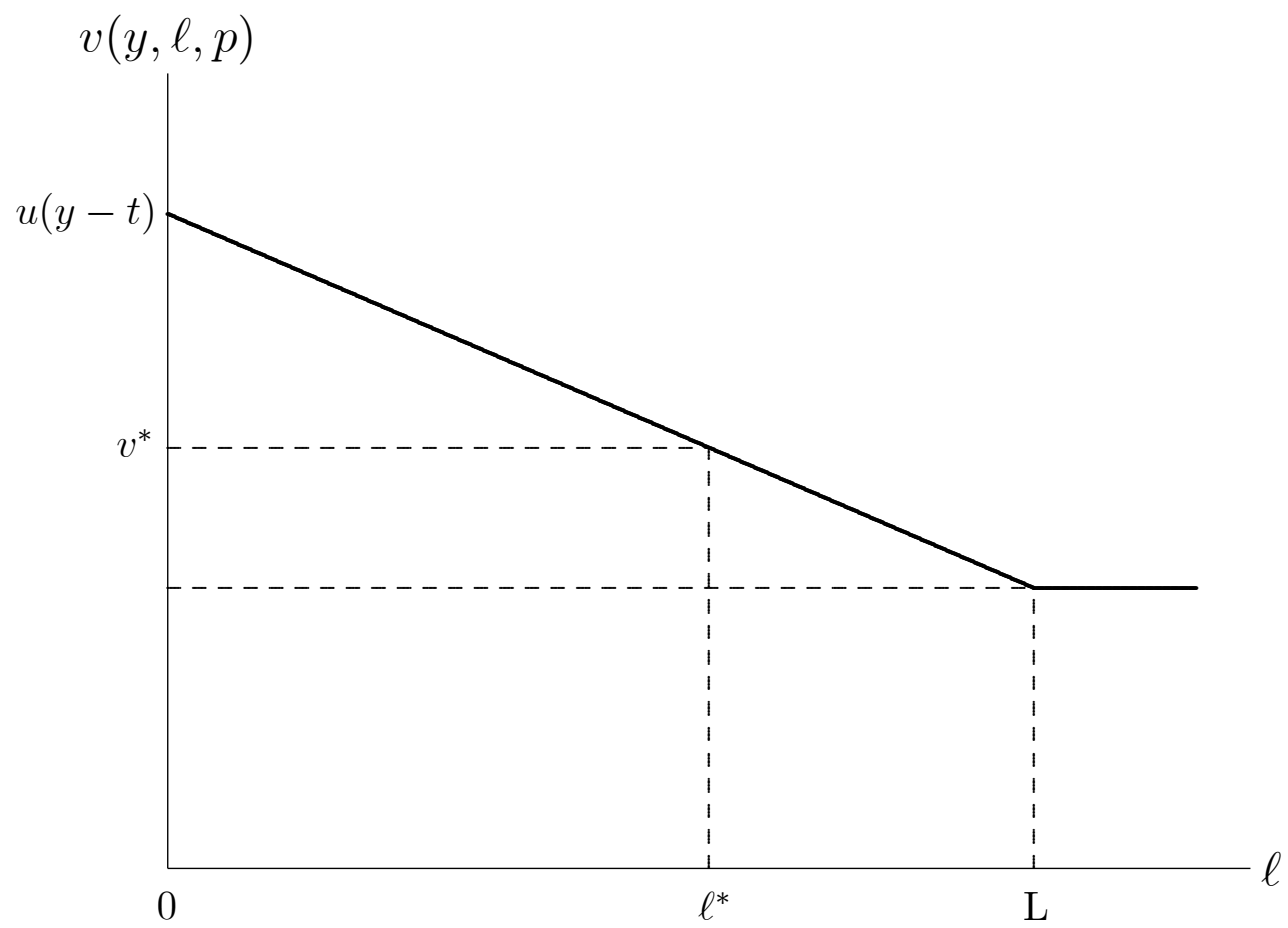

$$
\begin{aligned}
\Delta=\left[-t^{\prime}(p)\right] u^{\prime}(y-t) \int_{\ell<L} & \delta(v) d F(y, \ell) \\
& -\left[1+t^{\prime}(p)\right] u^{\prime}(y-t-p) \int_{\ell>L} \delta(v) d F(y, \ell)
\end{aligned}
$$

Moreover, (13) can in this case be written as

$$
\int_{\ell<L} \delta(v) d F(y, \ell)=-\int_{\ell>L} \delta(v) d F(y, \ell)<0
$$

since $\delta(v)>0$ for $\ell>L$. The first integral in (15) is in other words negative. The second integral in (15) is positive, since $\delta(v)>0$ for $\ell>L$. Since the terms $\left[-t^{\prime}(p)\right]$ and $\left[1+t^{\prime}(p)\right]$ are both positive, it follows that $\Delta<0$ in the present case. From our previous discussion we thus have the the following proposition: 
Proposition 2 Assume that incomes are identical in the population but preferences, represented by the variable $\ell$, differ among persons. Assume also that the initial optimal co-payment is such that some persons choose treatment while others choose not to be treated. In this case increased concern for equity reduces the optimal co-payment.

\subsection{Heterogeneous income}

In this special case we assume that the value of $\ell$ is the same for everyone, but that income $y$ varies in the population. Expected utility of a person therefore only depends on this person's income. A person with a "high" income (a value of $y$ satisfying the inequality (1)) will choose to be treated, and a person with a "low" income (a value of $y$ that does not satisfy the inequality (1)) will choose not to be treated. Expected utility $v$ will in this case be a strictly increasing function function of $y$, and the value of $y$ corresponding to $v^{*}$ is denoted by $y^{*}$. For this case $\delta(v)>0$ for $y<y^{*}$ and $\delta(v)<0$ for $y>y^{*}$. In words, marginal welfare weights are increased for persons with "low" income $\left(y<y^{*}\right)$ and reduced for persons with "high" income $\left(y>y^{*}\right)$.

Use $Y$ to denote the critical value of $y$ giving equality in (1). The expression (14) can then be written as

$$
\begin{aligned}
\Delta=\left[-t^{\prime}(p)\right] \int_{y<Y} \delta(v) u^{\prime}(y-t) d F(y, \ell) & \\
& -\left[1+t^{\prime}(p)\right] \int_{y>Y} \delta(v) u^{\prime}(y-t-p) d F(y, \ell)
\end{aligned}
$$

Just like for the general case, it is not possible to unambiguously sign $\Delta$ for this special case. However, there exist changes in the function $\Phi$ that make $\Delta$ unambiguously positive. Consider first the case where all of those who initially are treated get a lower marginal welfare weight after the change. In other words, $\delta(v)<0$ for $y>Y$. In this case the second integral in (17) is negative. In the first integral there are negative and positive values of $\delta(v)$. 
However, since $\delta(v) u^{\prime}(y-t)$ is lower the higher is $y$, it follows from (13) that the positive values dominate, i.e. that the first integral in (17) is positive. Since the terms $\left[-t^{\prime}(p)\right]$ and $\left[1+t^{\prime}(p)\right]$ are both positive, it follows that $\Delta>0$ in this case.

The case in which $\delta(v)<0$ for all who initially choose to be treated is obviously rather restrictive. However, even if some of those who choose to be treated get increased marginal welfare weights, the negative $\delta$-terms in the second integral may dominate the positive $\delta$-terms, so that the second integral remains negative. And even if so many of those treated get increased marginal welfare weights that the second integral becomes positive, $\Delta$ may still be positive since the first term in (17) is always positive. This leads to the following proposition:

Proposition 3 Assume that the value of $\ell$ is the same for everyone, but that income $y$ varies among persons. Assume also that the initial optimal co-payment is such that some persons choose treatment while others choose not to be treated. In this case increased concern for equity increases the optimal co-payment provided a sufficiently large number of persons who choose treatment get reduced marginal welfare weights.

\section{Interaction with a progressive tax system}

So far, we have only considered tax changes that were identical for everyone. This assumption may be justified as follows: Distributional considerations are achieved through distortionary taxation. The optimal design of a distortionary tax system implies that redistribution has been taken to the point where the social gain from further redistribution is exactly offset by the incremental distortion of higher rates of taxation. For an optimally designed tax system of this type, social welfare cannot be increased by increasing or reducing a tax component which is equal for all (and thus non-distortionary) and adjusting the distortionary part of the tax system so that total revenue is unchanged. On the margin, it therefore makes no difference whether an 
increase in health expenditures is financed by a non-distortionary tax increase (i.e. a tax increase that is the same for everyone) or by an increase in distortionary tax rates. The assumption that any change in the co-payment is balanced by a change in the tax rate $t$ that is the same for everyone is therefore less restrictive than it may immediately seem.

From the reasoning above it follows that as we vary the size of the copayment $p$, the change in social welfare (as measured by (11)) is independent of whether the variation in $p$ is matched by a change in $t$ or some other tax component in the tax system, as long as the tax system initially is optimally designed. However, since a change in $p$ normally will change all components of an optimally designed tax system, the change in expected utility for any particular person will be different from what we derived in Section 2. In particular, equations (7) and (8) and Proposition 1 will no longer be valid.

The first-order condition (12) for the optimal $p$ is valid also when all components of the tax system are optimally set. However, as the income term $y$ is gross income minus all taxes other than the tax component $t$, this income term will in this case depend on these other taxes as well as on the distribution of gross income. When social preferences become more equity oriented, it is reasonable to assume that the optimal tax system will be changed, implying a change in $y$ for any given level of gross income. The effect of this change in the distribution of $y$ is not taken into consideration in our analysis in Section 4.

The case considered in Section 4.1 will not be affected by the assumption that the tax system is optimally designed, since incomes in any case are identical in this case. Proposition 2 thus remains valid. For the case considered in 4.1 on the other hand, the derivations and results will generally be changed if the change in social preferences also changes the distribution of $y$. The main result hover, that the optimal co-payment might increase as a response to increased concern for equity, remains valid. To see this, consider the case where the distortionary costs of a progressive element of the tax system increase sharply once this progressive element reaches some threshold. If we are at this threshold before preferences are changes, increased concern for equity will only give a very small increase in this progressive element of 
the tax system. The change in the distribution of $y$ will therefore be very small, implying that the derivations in Section 4.1 remain almost the same as for the case where the progressive element of the tax system was assumed to be constant.

Even if the progressive element of a tax system increases significantly a response to increased concern for equity, the optimal co-payment may also increase. To see this, consider the following simple example. There are three groups in society: "Rich and very healthy", "poor and quite healthy" and "poor and weak". The "rich" never get ill, while the income and probability of illness is the same for two "poor" groups. For the "quite healthy", the utility loss in case of illness is much smaller for than the treatment cost, while the opposite is true for the "weak". In such an economy it will be socially optimal to give the "weak" treatment in the event of illness, while treatment for the "quite healthy" is inefficient. The co-payment should therefore be set so high that the "quite healthy" choose to go untreated in the case of illness. Given this constraint, the co-payment should be set as low as possible, in order to achieve income smoothing across states for the "weak".

Now consider an increased concern for equity. The tax system would then change so that the "rich" get lower income and both "poor" groups get higher income. Since the "quite healthy poor" now will get an increased willingness to pay for treatment, they will choose treatment if the co-payment is held constant at its original level. In order to prevent this socially inefficient outcome, the co-payment must be increased so much that the "quite healthy poor" continue to choose to go untreated, in spite of their increased income.

In the Appendix we give an alternative fully specified numerical example with a linear tax function where both the marginal tax rate and the copayment increase as a response to increased concern for equity.

\section{Concluding remarks}

In the Introduction, we argued that concern for equity is often used as an argument against any proposal of increasing co-payments for health treatment. By this logic, we would expect that increased concern for equity, as 
defined precisely in Section 4, should make optimal co-payments go down. We have shown that this need not be the case. On the contrary: With homogeneous preferences, Proposition 3 suggests that it is quite likely that optimal co-payments increase with more concern for equity.

When preferences for health care vary across people, it is not obvious in what direction optimal co-payments change when society's concern for equity increases. Proposition 2 suggests that in a country where income differences are small, optimal co-payments should be lower the stronger is society's concern for equity, at least for treatments for which preferences are rather heterogeneous.

We have used the term "preferences" and "severity of illness" interchangeable throughout the paper to describe the variable $\ell$. This has been deliberate: The way the model is set up, it seems natural to think of $\ell$ is a measure of the severity of an illness (if untreated). On the other hand, one can simply interpret $\ell$ as a parameter in (a special case of) a utility function where aggregate consumption $(y)$ and health care $(-\ell)$ enter, and where health care is only valued positively if one has some illness. In such a setting the value of the parameter $\ell$ will simply represent the willingness to pay for a treatment should one require it to avoid a specific illness. Also at the more practical side, one can interpret the variable $\ell$ differently. Consider for instance the case of prescription medicines. Some prescription medicines are good examples of a large heterogeneity in the population regarding the benefits of the medicine. In many cases a new and more costly medicine will have the same primary medical effect as a medicine already in use. However, the new medicine may have weaker unpleasant side effects. Such side effects very often vary strongly among different patients, being non-existent or weak for some, and very severe for others. In this case it is natural to regard the variable $\ell$ as a measure of severity of an illness. A different example is a couple who can only have children through assisted fertilization. The term $\ell$ is in this case a variable reflecting how much worse of the couple feels without children than with, i.e. a variable measuring the strength of the preferences for having children.

The degree of heterogeneity of preferences in a society is likely to vary 
a lot between different types of illnesses. Although the formal model used in the present analysis only considers one type of illness, Propositions 2 and 3 suggest the following result: If a society becomes more concerned about equity, it may be optimal to reduce co-payments for some types of treatments but at the same time increase co-payments for other treatments. 


\section{Appendix: A numerical example}

Consider an economy where the average gross income is 1 . There are two equally sized groups. Group 1 has income 1.5, while group 2 has income 0.5. The probability of illness is 0.1 , and the treatment cost is 1 . The utility loss in case of illness for group 1 is so large that treatment is chosen no matter how high the co-payment is, while there is no utility loss for group 2.

There are two tax parameters: The tax $t$ that is equal for everyone, and a proportional income $\operatorname{tax} \tau$. There is a deadweight loss associated with $\tau$, implying that the tax function (4) now becomes

$$
t=0.1 \cdot(1-p) \cdot 0.5-\left[\tau-\tau^{2}\right]
$$

The term in square brackets is the income revenue (per capita) due to the proportional tax (since average income is 1 ). The last term $\left(\tau^{2}\right)$ represents the deadweight loss due to the distortion implied by the income tax. This distortion implies that the top of the "Laffer curve" for this tax component is at $\tau=0.5$.

Net incomes for the two groups are (using $(18))^{4}$

$$
y_{1}=1.5-1.5 \tau-t=1.450-0.5 \tau-\tau^{2}+0.05 p
$$

and

$$
y_{2}=0.5-0.5 \tau-t=0.450+0.5 \tau-\tau^{2}+0.05 p
$$

Notice that whatever $p$ is, $y_{1}$ declines and $y_{2}$ rises as $\tau$ increases, as long as $\tau<0.25$. However, for $\tau>0.25$ both net incomes decline as $\tau$ increases. In a social optimum it therefore must be the case that $\tau<0.25$.

The utility function is $u(x)=\ln x$ for both groups. Expected utility levels for the two groups are

$$
v_{1}=0.9 \ln \left[1.450-0.5 \tau-\tau^{2}+0.05 p\right]+0.1 \ln \left[1.450-0.5 \tau-\tau^{2}-0.95 p\right]
$$

\footnotetext{
${ }^{4}$ Notice that we have subtracted also the constant tax $t$ in this definition of net income, unlike what we did in the main text.
} 
and

$$
v_{2}=\ln \left[0.450+0.5 \tau-\tau^{2}+0.05 p\right]
$$

It is easily verified that $v_{1}>v_{2}$ for all $\tau \in[0,0.25]$ and $p \in[0,1]$. In the social welfare function group 2 should therefore be given at least as large weight as group 1. Since there are only two groups, it is easier to work with exogenous welfare weights than the concave function used in Sections 3-4. The social welfare function is thus

$$
W=v_{1}+\gamma v_{2}
$$

where $\gamma \geq 1$.

The optimal value of $W$ is obtained by solving the following equations:

$$
\begin{aligned}
\frac{\partial W}{\partial p} & =\frac{0.045}{y_{1}}-\frac{0.095}{y_{1}-p}+\frac{0.05 \gamma}{y_{2}}=0 \\
\frac{\partial W}{\partial \tau} & =\frac{0.9(-0.5-2 \tau)}{y_{1}}+\frac{0.1(-0.5-2 \tau)}{y_{1}-p}+\frac{\gamma(0.5-2 \tau)}{y_{2}}=0
\end{aligned}
$$

for $p \in[0,1], \tau \in[0,0.25]$, given $\gamma$. A numerical solution for the optimizing problem for different values of $\gamma$ is found using Maple (s.t. $\tau \in[0,0.25]$ and $p \in[0,1])$ :

$$
\begin{array}{llll} 
& \tau & p & W \\
\gamma=1 & .1062872413 & .6703546385 & -.3575958178 \\
\gamma=1.5 & .1357928137 & .8486112171 & -.6707438076 \\
\gamma=1.75 & .1455947627 & .9067929325 & -.8227024058
\end{array}
$$

From this table it is clear that as the concern for equity (measured by $\gamma$ ) increases, we get an increase in both the optimal marginal tax and the optimal co-payment. 


\section{References}

Arrow, K. (1963), Uncertainty and the welfare economics of medical care. American Economic Review 53, 941-973.

Arrow, K. (1968), The economics of moral hazard: Further comment. American Economic Review 58, 537-539.

Ma, C.A. and M.H Riordan (2002), Health insurance, moral hazard and managed care. Journal of Economics \& Management Strategy 11, 81107.

Pauly, M.V. (1968), The economics of moral hazard: Comment. American Economic Review 58, 531-537.

Shavell, S. (1979), On moral hazard and insurance. Quarterly Journal of Economics 93, 541-562.

Zeckhauser, R. (1970), Medical insurance: A case study of the tradeoff between risk spreading and the appropriate incentives. Journal of Economic Theory 2, 10-26. 


\section{CESifo Working Paper Series}

(for full list see www.cesifo-group.de)

1557 Piotr Wdowinski, Financial Markets and Economic Growth in Poland: Simulations with an Econometric Model, October 2005

1558 Peter Egger, Mario Larch, Michael Pfaffermayr and Janette Walde, Small Sample Properties of Maximum Likelihood Versus Generalized Method of Moments Based Tests for Spatially Autocorrelated Errors, October 2005

1559 Marie-Laure Breuillé and Robert J. Gary-Bobo, Sharing Budgetary Austerity under Free Mobility and Asymmetric Information: An Optimal Regulation Approach to Fiscal Federalism, October 2005

1560 Robert Dur and Amihai Glazer, Subsidizing Enjoyable Education, October 2005

1561 Carlo Altavilla and Paul De Grauwe, Non-Linearities in the Relation between the Exchange Rate and its Fundamentals, October 2005

1562 Josef Falkinger and Volker Grossmann, Distribution of Natural Resources, Entrepreneurship, and Economic Development: Growth Dynamics with Two Elites, October 2005

$1563 \mathrm{Yu}-\mathrm{Fu}$ Chen and Michael Funke, Product Market Competition, Investment and Employment-Abundant versus Job-Poor Growth: A Real Options Perspective, October 2005

1564 Kai A. Konrad and Dan Kovenock, Equilibrium and Efficiency in the Tug-of-War, October 2005

1565 Joerg Breitung and M. Hashem Pesaran, Unit Roots and Cointegration in Panels, October 2005

1566 Steven Brakman, Harry Garretsen and Marc Schramm, Putting New Economic Geography to the Test: Free-ness of Trade and Agglomeration in the EU Regions, October 2005

1567 Robert Haveman, Karen Holden, Barbara Wolfe and Andrei Romanov, Assessing the Maintenance of Savings Sufficiency Over the First Decade of Retirement, October 2005

1568 Hans Fehr and Christian Habermann, Risk Sharing and Efficiency Implications of Progressive Pension Arrangements, October 2005

1569 Jovan Žamac, Pension Design when Fertility Fluctuates: The Role of Capital Mobility and Education Financing, October 2005

1570 Piotr Wdowinski and Aneta Zglinska-Pietrzak, The Warsaw Stock Exchange Index WIG: Modelling and Forecasting, October 2005 
1571 J. Ignacio Conde-Ruiz, Vincenzo Galasso and Paola Profeta, Early Retirement and Social Security: A Long Term Perspective, October 2005

1572 Johannes Binswanger, Risk Management of Pension Systems from the Perspective of Loss Aversion, October 2005

1573 Geir B. Asheim, Wolfgang Buchholz, John M. Hartwick, Tapan Mitra and Cees Withagen, Constant Savings Rates and Quasi-Arithmetic Population Growth under Exhaustible Resource Constraints, October 2005

1574 Christian Hagist, Norbert Klusen, Andreas Plate and Bernd Raffelhueschen, Social Health Insurance - the Major Driver of Unsustainable Fiscal Policy?, October 2005

1575 Roland Hodler and Kurt Schmidheiny, How Fiscal Decentralization Flattens Progressive Taxes, October 2005

1576 George W. Evans, Seppo Honkapohja and Noah Williams, Generalized Stochastic Gradient Learning, October 2005

1577 Torben M. Andersen, Social Security and Longevity, October 2005

1578 Kai A. Konrad and Stergios Skaperdas, The Market for Protection and the Origin of the State, October 2005

1579 Jan K. Brueckner and Stuart S. Rosenthal, Gentrification and Neighborhood Housing Cycles: Will America’s Future Downtowns be Rich?, October 2005

1580 Elke J. Jahn and Wolfgang Ochel, Contracting Out Temporary Help Services in Germany, November 2005

1581 Astri Muren and Sten Nyberg, Young Liberals and Old Conservatives - Inequality, Mobility and Redistribution, November 2005

1582 Volker Nitsch, State Visits and International Trade, November 2005

1583 Alessandra Casella, Thomas Palfrey and Raymond Riezman, Minorities and Storable Votes, November 2005

1584 Sascha O. Becker, Introducing Time-to-Educate in a Job Search Model, November 2005

1585 Christos Kotsogiannis and Robert Schwager, On the Incentives to Experiment in Federations, November 2005

1586 Søren Bo Nielsen, Pascalis Raimondos-Møller and Guttorm Schjelderup, Centralized vs. De-centralized Multinationals and Taxes, November 2005

1587 Jan-Egbert Sturm and Barry Williams, What Determines Differences in Foreign Bank Efficiency? Australian Evidence, November 2005 
1588 Steven Brakman and Charles van Marrewijk, Transfers, Non-Traded Goods, and Unemployment: An Analysis of the Keynes - Ohlin Debate, November 2005

1589 Kazuo Ogawa, Elmer Sterken and Ichiro Tokutsu, Bank Control and the Number of Bank Relations of Japanese Firms, November 2005

1590 Bruno Parigi and Loriana Pelizzon, Diversification and Ownership Concentration, November 2005

1591 Claude Crampes, Carole Haritchabalet and Bruno Jullien, Advertising, Competition and Entry in Media Industries, November 2005

1592 Johannes Becker and Clemens Fuest, Optimal Tax Policy when Firms are Internationally Mobile, November 2005

1593 Jim Malley, Apostolis Philippopoulos and Ulrich Woitek, Electoral Uncertainty, Fiscal Policy and Macroeconomic Fluctuations, November 2005

1594 Assar Lindbeck, Sustainable Social Spending, November 2005

1595 Hartmut Egger and Udo Kreickemeier, International Fragmentation: Boon or Bane for Domestic Employment?, November 2005

1596 Martin Werding, Survivor Benefits and the Gender Tax Gap in Public Pension Schemes: Observations from Germany, November 2005

1597 Petra Geraats, Transparency of Monetary Policy: Theory and Practice, November 2005

1598 Christian Dustman and Francesca Fabbri, Gender and Ethnicity - Married Immigrants in Britain, November 2005

1599 M. Hashem Pesaran and Martin Weale, Survey Expectations, November 2005

1600 Ansgar Belke, Frank Baumgaertner, Friedrich Schneider and Ralph Setzer, The Different Extent of Privatisation Proceeds in EU Countries: A Preliminary Explanation Using a Public Choice Approach, November 2005

1601 Jan K. Brueckner, Fiscal Federalism and Economic Growth, November 2005

1602 Steven Brakman, Harry Garretsen and Charles van Marrewijk, Cross-Border Mergers and Acquisitions: On Revealed Comparative Advantage and Merger Waves, November 2005

1603 Erkki Koskela and Rune Stenbacka, Product Market Competition, Profit Sharing and Equilibrium Unemployment, November 2005

1604 Lutz Hendricks, How Important is Discount Rate Heterogeneity for Wealth Inequality?, November 2005 
1605 Kathleen M. Day and Stanley L. Winer, Policy-induced Internal Migration: An Empirical Investigation of the Canadian Case, November 2005

1606 Paul De Grauwe and Cláudia Costa Storti, Is Monetary Policy in the Eurozone less Effective than in the US?, November 2005

1607 Per Engström and Bertil Holmlund, Worker Absenteeism in Search Equilibrium, November 2005

1608 Daniele Checchi and Cecilia García-Peñalosa, Labour Market Institutions and the Personal Distribution of Income in the OECD, November 2005

1609 Kai A. Konrad and Wolfgang Leininger, The Generalized Stackelberg Equilibrium of the All-Pay Auction with Complete Information, November 2005

1610 Monika Buetler and Federica Teppa, Should you Take a Lump-Sum or Annuitize? Results from Swiss Pension Funds, November 2005

1611 Alexander W. Cappelen, Astri D. Hole, Erik Ø. Sørensen and Bertil Tungodden, The Pluralism of Fairness Ideals: An Experimental Approach, December 2005

1612 Jack Mintz and Alfons J. Weichenrieder, Taxation and the Financial Structure of German Outbound FDI, December 2005

1613 Rosanne Altshuler and Harry Grubert, The Three Parties in the Race to the Bottom: Host Governments, Home Governments and Multinational Companies, December 2005

1614 Chi-Yung (Eric) Ng and John Whalley, Visas and Work Permits: Possible Global Negotiating Initiatives, December 2005

1615 Jon H. Fiva, New Evidence on Fiscal Decentralization and the Size of Government, December 2005

1616 Andzelika Lorentowicz, Dalia Marin and Alexander Raubold, Is Human Capital Losing from Outsourcing? Evidence for Austria and Poland, December 2005

1617 Aleksander Berentsen, Gabriele Camera and Christopher Waller, Money, Credit and Banking, December 2005

1618 Egil Matsen, Tommy Sveen and Ragnar Torvik, Savers, Spenders and Fiscal Policy in a Small Open Economy, December 2005

1619 Laszlo Goerke and Markus Pannenberg, Severance Pay and the Shadow of the Law: Evidence for West Germany, December 2005

1620 Michael Hoel, Concerns for Equity and the Optimal Co-Payments for Publicly Provided Health Care, December 2005 